\title{
Knowledge, attitude, and preventive behaviors of Hormozgan residents toward COVID-19, one month after the epidemic in Iran
}

\author{
Nahid Shahabi ${ }^{1} \cdot$ Hesamaddin Kamalzadeh Takhti ${ }^{2}$ - Mehdi Hassani Azad ${ }^{3} \cdot$ Roghayeh Ezati Rad $^{1}$. \\ Hamid Reza Ghaffari ${ }^{4}$. Shokrollah Mohseni ${ }^{4} \cdot$ Teamur Aghamolaei $^{5} \cdot$ Fatemeh Norozian $^{4}$
}

Received: 27 May 2020 / Accepted: 2 December 2020 / Published online: 7 January 2021

(C) The Author(s), under exclusive licence to Springer-Verlag GmbH, DE part of Springer Nature 2021

\begin{abstract}
Aim COVID-19 has become prevalent in the world since December 2019. The further prevalence of the disease can be prevented by correct management of society and increasing knowledge, practices, and attitudes of the people. The present research aimed to evaluate the knowledge, attitudes, and preventive behaviors of people in Hormozgan in the south of Iran toward COVID-19.

Subject and methods The present cross-sectional research was conducted over 2 months (March 2020-April 2020). The online questionnaire comprised four sections: demographic information, knowledge, attitude, and behavior toward COVID-19. Knowledge included 36 items, attitude eight items, and behavior ten items. The collected data were analyzed statistically using SPSS ver. 22. The split-half method was used to test the reliability of knowledge and the estimated value was 0.84 . That of attitude and behavior was estimated via Cronbach's alpha and was found to be 0.81 and 0.75 , respectively.

Results A total number of 2024 participants with an average age of 33.94 years took part in this research. Of all participants, $64.4 \%$ were female. According to the results, $65.8 \%$ enjoyed a good level of knowledge and $34.2 \%$ enjoyed an average level. In addition, $63.2 \%$ demonstrated a good attitude and $36.8 \%$ an average level. A large percentage of participants (90.6\%) had good practices and only $9.4 \%$ had an average level of practices.

Conclusion The present findings show that participants had a relatively good level of knowledge, positive attitude, and good behavior concerning COVID-19.
\end{abstract}

Keywords Knowledge $\cdot$ Attitude $\cdot$ Preventive behavior $\cdot$ COVID-19

\section{Introduction}

In early December 2019, certain cases of pneumonia were reported in the city of Wuhan, Hubei Province, China

Teamur Aghamolaei

teaghamolaei@gmail.com

1 Student Research Committee, Faculty of Health, Hormozgan University of Medical Sciences, Bandar Abbas, Iran

2 Department of Community Medicine, School of Medicine, Hormozgan University of Medical Sciences, Bandar Abbas, Iran

3 Infectious and Tropical Diseases Research Center, Hormozgan Health Institute, Hormozgan University of Medical Sciences, Bandar Abbas, Iran

4 Social Determinants in Health Promotion Research Center, Hormozgan Health Institute, Hormozgan University of Medical Sciences, Bandar Abbas, Iran

5 Cardiovascular Research Center, Hormozgan University of Medical Sciences, Bandar Abbas, Iran
(Chinazzi et al. 2020). The reports originated from a fresh sea food market in Wuhan, China (Wolf et al. 2020). Investigations revealed that the disease was induced by a new beta coronavirus marked by a $79 \%$ genome sequence of SARS-CoV, which was formerly highly prevalent in 2002 2003. As suggested by the Coronavirus Study Group (CSG) of the International Committee, this virus was classified based on the genome sequence and due to its activity, and it was named SARS-CoV-2 (Gorbalenya et al. 2020; Lake 2020; Wu et al. 2020). On 11 February 2020, the World Health Organization (WHO) formally announced this disease as COVID-19 (WHO 2020b).

As of 16 November 2020 confirmed COVID-19 cases were 54,301,156 and the worldwide mortality rate of this disease was reported to be $1,316,994$. As of this date, the number of afflicted in Iran was 762,068 and the mortality rate was 41,493 (WHO 2020a).

Although the relationship between the prevalence of COVID 19 and climatic conditions has been hypothesized, there is a lack of agreement in studies regarding the effect of 
weather conditions on the infection rate of the disease and its resulting mortality. In the study by Shahzad et al., the relationship between temperature and COVID-19 was positive for four cities, negative for two provinces, and showed mixed trends for five provinces (Shahzad et al. 2020). In another study, by Tosepu et al., relating to weather conditions, including temperature, humidity, and rainfall, only average temperature was significantly associated with COVID-19 (Tosepu et al. 2020).

It is not possible to study the relationship between weather conditions and the prevalence of COVID-19 in Iran due to the lack of official data of morbidity and mortality of COVID- 19 . The outbreak first started in the cold months of the year in the northern and central regions of Iran (Gilan, Mazandaran, Tehran, and Qom). Shortly thereafter, cases of the disease were observed in all provinces of the country. However, the prevalence of this disease in the southern provinces (Hormozgan, Bushehr, and Khuzestan) with hot and humid climate has intensified with the onset of the hot season. According to an unconfirmed hypothesis, the increase in cases and deaths from COVID-19 in hot and humid provinces has been linked to the presence of people indoors for longer periods of time and the transmission of the virus over longer distances by ventilation systems.

The key transmission routes are oral and nasal droplets or exposure to contaminated surfaces. The average incubation of the disease is 6.4 days (2.1-11.1 days) (Backer et al. 2020). It is also mentioned that the virus may survive for 14 days on some surfaces (Lauer et al. 2020; Xiao et al. 2020).

The best way to overcome the disease is to control the sources of infection (Choi and Kim 2016; Tao et al. 2020). Controlling strategies are early diagnosis, report, quarantine, and supportive treatments. Protective measures include avoidance of close and direct contact with the patients, frequent hand washing with soap and water, avoidance of unprotected contact with domestic and wild animals, and the use of face masks.

Promotion of the knowledge, attitude, and behavior of social members concerning different aspects of COVID-19 can help to take effective steps to develop correct healthy behaviors and increase public adherence to medical advice to prevent the spread of the disease (Ajilore et al. 2017; Yaghubi et al. 2014; Zhong et al. 2020). Experiences of the prevalence of SARS in 2003 and MERS in 2012 show that inadequate knowledge and negative attitudes toward the disease would induce a feeling of fear of the disease and labeling of patients in society. This fear can complicate attempts for preventing the prevalence of the disease. Thus, there is a need for planning awareness-raising programs to improve attitudes and practices of the health staff and medical personnel as well as the public (Alsahafi and Cheng 2016; Kim 2017; Person et al. 2004; Zhong et al. 2020). Knowledge about a disease can affect an individual's attitude and intention, and intention would directly affect an individual's behavior. Thus, lacking knowledge and a correct attitude can lead to inappropriate practice and can increase the risk of infection (McEachan et al. 2016). Currently, a key step to prevent the national epidemic is to offer the required effective instructions to increase knowledge and attitudes concerning the symptoms, side effects, and transmission routes for different social classes and appropriate practice in this regard (Adab et al. 2016).

Accordingly, the present research aimed to evaluate the knowledge, attitudes, and preventive behaviors of the residents of Hormozgan Province, in the south of Iran concerning COVID-19.

\section{Methods}

\section{Research design}

This cross-sectional study was conducted over 2 months (March 2020-April 2020). The target population was residents of Hormozgan Province aged above 15 years. Hormozgan is a province in the south of Iran with a population of 177,641,500 according to the census in 2017.

\section{Data collection}

To avoid the chances of transmitting COVID-19 through paper-based questionnaires, online questionnaires were used. The questionnaire internet-based links were made available to participants via social networks or email addresses. The participants were asked to fill out the online questionnaires. The questionnaire included four sections: demographic information, knowledge, attitude, and preventive behaviors concerning COVID-19. Demographic information included age, gender, occupation, education, place of residence, marital status, and the history of chronic diseases.

The knowledge part of the questionnaire was explored via 36 items addressing the common symptoms of the disease, individuals at risk, transmission routes and preventing the disease, and wearing masks. Each item could be answered by choosing among three options: true/false/do not know. Each true answer would be scored as 1 whereas each false or do not know answer would receive 0 . The range of score for this part of the questionnaire was 0 to 36 .

The attitude part included eight items to be rated on a Likert scale with five options: strongly agree, agree, no opinion, disagree, and strongly disagree. The score for each attitude item would range between 1 and 5. Thus, the range of attitude score would be 8 to 40 .

The preventive behaviors part of the questionnaire comprised ten items that explored the prevention of COVID-19. The participants were asked to answer each item by choosing among five options: never, seldom, sometimes, often, and 
always. The score for each behavioral item ranged between 0 and 4 . Therefore, the whole behavior part was scored between 0 and 40 .

In rating knowledge, attitude and practice, a score between $0 \%$ and $50 \%$ was considered low; that between $51-75 \%$ was interpreted as average; and above $75 \%$ was taken as good. Because there were no scores below $50 \%$, the scores were finally classified into two groups: good and average.

The validity of the questionnaire was confirmed through content validation by a panel of experts. To test the reliability of the knowledge items the split-half method was used. In fact, 30 items were randomly selected and once the questionnaires were completed, they were divided in two halves and the correlation coefficient between the two halves was calculated and it was 0.84 . To test the reliability of attitude and behavior, Cronbach's alpha test was run and it was 0.81 and 0.75 , respectively.

\section{Results}

\section{Demographic information}

In total, 2024 participants took part in the present research and filled out the questionnaires. They aged between 15 and 75 years. The average age was $33.94 \pm 9.37$ years. The highest frequencies belonged to the 31-40 years age group. Of all participants, $64.4 \%$ were female and $35.6 \%$ were male. Also, $27.1 \%$ of the participants were single and the rest were married. As for education, the highest frequency (59.2\%) was observed in the "B.S. or above" group. Approximately half (44.4\%) of the participants worked for governmental offices. Furthermore, $19.9 \%$ were health personnel. A total of $85.5 \%$ resided in urban areas. Social networks were the main source of obtaining information about COVID-19 and were used by $49.2 \%$ of the participants. Details on demographic information are presented in Table 1.

\section{Participants' knowledge}

There were 36 items in the knowledge part of the questionnaire exploring the common symptoms of disease, people at risk, preventive measures, transmission routes, and using masks. As seen in Table 2, from among the 36 points that could be scored in the knowledge part, the mean score obtained was 28.57. As the classification showed, 1332(65.8\%) of the participants belonged to the good category and 692 $(34.2 \%)$ belonged to the average category.

Between the mean knowledge score of men and women, married and single, different age groups, different occupational groups, and different education levels, statistically significant differences were observed. The T-test and ANOVA results are shown in Table 3.
Knowledge of different aspects of COVID-19 is represented in Fig. 1. Concerning knowledge of the symptoms of COVID-19, more than $97 \%$ of participants showed a sound knowledge of fever and dry coughs.

Concerning the at risk groups, more than $80 \%$ of individuals mentioned those with a cardiovascular disease, diabetes or above 60 years of age as the population at risk of COVID-19.

Participants demonstrated a good knowledge of the routes through which COVID-19 could be transmitted, as more than $90 \%$ of the participants mentioned the transmission routes such as contaminated surfaces and oral/nasal droplets.

As seen in Fig. 1, most measures recommended to prevent the disease such as washing hands with soap and water, no kissing/ embracing while greeting, hiding face while coughing or sneezing, social distancing, staying at home, and not entering crowded places were chosen by more than $97 \%$ of the participants.

More than $97 \%$ of participants mentioned wearing masks was essential for patients, suspected patients, medical staff, caregivers, and the public while attending crowded places.

\section{Participants' attitude}

There were eight items in the attitude part of the questionnaire, which was about the adverse effects, risk, exposure to infection, effect of heat, effect of antibiotic consumption, entering crowded places, effect of drinking alcohol, and travel in relation to COVID-19. The maximum score that could be obtained was 40. According to Table 2, the mean score of this part of the questionnaire was 32.02 and the results revealed that 1280 $(63.2 \%)$ of participants were classified as good and 744 $(36.8 \%)$ as average.

The mean attitude score was significantly different in different occupations, medical staff and others, urban and rural residents, education levels, and age groups. Table 3 shows Ttest and ANOVA results to compare groups.

According to Figs. 2, 39\% and $27.5 \%$ of participants, respectively, strongly disagreed and strongly agreed with the item "Coronavirus is like a simple cold and has no dangerous side effects."

Concerning attitude toward "I have a strong body, so even if I get the coronavirus, it's not dangerous for me.", $27 \%$ strongly disagreed, 24\% disagreed, and only $9 \%$ strongly agreed.

A majority of participants (85\%) agreed with "Everyone is at the risk of coronavirus" and had an accurate attitude toward the disease.

As it can be observed in Figs. 2, 68\% of the participants disagreed and strongly disagreed with the effect of the hot weather of Hormozgan on the risk of the disease.

Approximately $76 \%$ of the participants disagreed with taking antibiotics to prevent infection with coronavirus. About $90 \%$ of the participants strongly agreed that people are more prone to the transmission of coronavirus in crowded places. Also, $55 \%$ of the participants believed that drinking alcohol 
Table 1 Participants' demographic information

\begin{tabular}{|c|c|c|c|}
\hline Demographic information & Category & Frequency & Percentage \\
\hline \multirow[t]{5}{*}{ Age } & $\leq 20$ year & 161 & 8.0 \\
\hline & $21-30$ year & 552 & 27.3 \\
\hline & $31-40$ year & 893 & 44.1 \\
\hline & $41-50$ year & 331 & 16.4 \\
\hline & $51-75$ year & 87 & 4.3 \\
\hline \multirow[t]{2}{*}{ Gender } & Male & 720 & 35.6 \\
\hline & Female & 1304 & 64.4 \\
\hline \multirow[t]{3}{*}{ Marital status } & Single & 548 & 27.1 \\
\hline & Married & 1444 & 71.3 \\
\hline & Divorced/widowed & 32 & 1.6 \\
\hline \multirow[t]{5}{*}{ Level of education } & Elementary & 27 & 1.3 \\
\hline & High school & 158 & 7.8 \\
\hline & Diploma & 423 & 20.9 \\
\hline & Associate Degree & 218 & 10.8 \\
\hline & Bachelor's degree and higher & 1198 & 59.2 \\
\hline \multirow[t]{6}{*}{ Job } & Student & 106 & 5.2 \\
\hline & University student & 118 & 5.8 \\
\hline & Employee & 898 & 44.4 \\
\hline & Self-employed & 264 & 13.0 \\
\hline & Unemployed & 273 & 13.5 \\
\hline & Others & 365 & 18.0 \\
\hline \multirow[t]{2}{*}{ Medical staff } & Yes & 402 & 19.9 \\
\hline & No & 1622 & 80.1 \\
\hline \multirow[t]{2}{*}{ Chronic diseases } & Yes & 332 & 16.4 \\
\hline & No & 1692 & 83.6 \\
\hline \multirow[t]{2}{*}{ Place of residence } & Urban & 1731 & 85.5 \\
\hline & Rural & 293 & 14.5 \\
\hline \multirow[t]{3}{*}{ The key source of knowledge } & Radio/TV & 813 & 40.2 \\
\hline & Ministry of Health & 215 & 10.6 \\
\hline & Social media & 996 & 49.2 \\
\hline
\end{tabular}

has no effect on the prevention of the virus. A total of $90 \%$ of participants agreed with "Travelling is effective in transmitting coronavirus."

\section{Participants' practice}

As indicated in Table 2, the mean score that participants obtained from the ten items exploring the practice part of the

Table 2 Mean knowledge, attitude, and practice scores of participants regarding COVID-19

\begin{tabular}{llrll}
\hline Variables & Mean \pm SD & $\begin{array}{c}\text { Min- } \\
\text { Max }\end{array}$ & Medium & Good \\
\hline Knowledge & $28.57 \pm 3.486$ & $5-36$ & $692(34.2)$ & $1332(65.8)$ \\
Attitude & $32.02 \pm 4.460$ & $15-40$ & $744(36.8)$ & $1280(63.2)$ \\
Behavior/practice & $36.84 \pm 5.008$ & $0-40$ & $191(9.4)$ & $1833(90.6)$ \\
\hline
\end{tabular}

questionnaire including personal protection behaviors was 36.84. As the classification showed, 1833 (90.6\%) of the participants were classified as good and only 191 (9.4\%) were classified as average.

According to Table 3 that includes T-test ANOVA results, the mean practice score of different jobs, marital status, place of residence, education levels, belonging or not belonging to medical staff, different sources of information (TV, the internet, Ministry of Health), and age groups showed statistically significant differences.

According to Fig. 3, concerning the statement "I only leave home for essential work," $70.2 \%$ showed to always do accordingly and $13 \%$ mentioned that they often did so.

Of all participants, $89.6 \%$ stated that they always avoid touching or kissing others. As seen in Figure, $92.5 \%$ of the participants always and often avoided touching eyes, mouth or nose. Among the respondents, 91.2\% always and often considered 1-2 m social distance from others. 
Table 3 Correlation between knowledge, attitude, and behavior concerning COVID-19 and demographic characteristics

\begin{tabular}{|c|c|c|c|c|c|c|c|}
\hline \multirow[t]{2}{*}{ Demographic characteristics } & \multirow[t]{2}{*}{ Category } & \multicolumn{2}{|l|}{ Knowledge } & \multicolumn{2}{|l|}{ Attitude } & \multicolumn{2}{|l|}{ Practice } \\
\hline & & Mean $\pm \mathrm{SD}$ & $\mathrm{p}$ & Mean \pm SD & $\mathrm{p}$ & Mean $\pm \mathrm{SD}$ & $\mathrm{p}$ \\
\hline \multirow[t]{4}{*}{ Age } & $\begin{array}{l}\leq 20 \text { year } \\
21-30 \text { year }\end{array}$ & $\begin{array}{l}26.65 \pm 3.993 \\
28.44 \pm 3.394\end{array}$ & \multirow[t]{4}{*}{$<0.001$} & $\begin{array}{l}30.75 \pm 4.488 \\
32.20 \pm 4.418\end{array}$ & \multirow[t]{4}{*}{0.001} & $\begin{array}{l}34.26 \pm 6.583 \\
36.50 \pm 5.329\end{array}$ & \multirow[t]{4}{*}{$<0.001$} \\
\hline & $31-40$ year & $28.67 \pm 3.260$ & & $31.97 \pm 4.441$ & & $37.13 \pm 4.794$ & \\
\hline & $41-50$ year & $29.34 \pm 3.591$ & & $32.50 \pm 4.481$ & & $37.71 \pm 3.685$ & \\
\hline & $51-75$ year & $29.10 \pm 3.596$ & & $31.87 \pm 4.430$ & & $37.51 \pm 4.406$ & \\
\hline Gender & $\begin{array}{l}\text { Male } \\
\text { Female }\end{array}$ & $\begin{array}{l}28.39 \pm 3.532 \\
28.68 \pm 3.457\end{array}$ & 0.075 & $\begin{array}{l}31.85 \pm 4.447 \\
32.11 \pm 4.466\end{array}$ & 0.206 & $\begin{array}{l}36.84 \pm 4.620 \\
36.84 \pm 5.211\end{array}$ & 0.999 \\
\hline \multirow[t]{2}{*}{ Marital status } & $\begin{array}{l}\text { Single } \\
\text { Married }\end{array}$ & $\begin{array}{l}28.21 \pm 3.558 \\
28.73 \pm 3.457\end{array}$ & \multirow[t]{2}{*}{0.003} & $\begin{array}{l}31.99 \pm 4.450 \\
32.04 \pm 4.447\end{array}$ & \multirow[t]{2}{*}{0.806} & $\begin{array}{l}36.37 \pm 5.161 \\
37.04 \pm 4.904\end{array}$ & \multirow[t]{2}{*}{0.020} \\
\hline & Divorced/widowed & $27.59 \pm 2.961$ & & $31.53 \pm 5.255$ & & $36.13 \pm 6.384$ & \\
\hline \multirow[t]{4}{*}{ Highest level of education } & $\begin{array}{l}\text { Elementary } \\
\text { High school }\end{array}$ & $\begin{array}{l}26.19 \pm 3.669 \\
26.39 \pm 3.857\end{array}$ & \multirow[t]{4}{*}{$<0.001$} & $\begin{array}{l}29.48 \pm 4.619 \\
30.61 \pm 4.791\end{array}$ & \multirow[t]{4}{*}{$<0.001$} & $\begin{array}{l}36.19 \pm 6.475 \\
34.54 \pm 7.240\end{array}$ & \multirow[t]{4}{*}{$<0.001$} \\
\hline & Diploma & $27.43 \pm 3.549$ & & $31.06 \pm 4.688$ & & $35.98 \pm 5.525$ & \\
\hline & Associate degree & $28.15 \pm 3.887$ & & $31.95 \pm 4.279$ & & $36.54 \pm 5.327$ & \\
\hline & Bachelor's degree or higher & $29.40 \pm 3.029$ & & $32.61 \pm 4.242$ & & $37.52 \pm 4.153$ & \\
\hline \multirow[t]{5}{*}{ Job } & $\begin{array}{l}\text { Student } \\
\text { University student }\end{array}$ & $\begin{array}{l}26.18 \pm 4.322 \\
28.38 \pm 3.422\end{array}$ & \multirow[t]{5}{*}{$<0.001$} & $\begin{array}{l}30.57 \pm 4.294 \\
32.26 \pm 4.640\end{array}$ & \multirow[t]{5}{*}{$<0.001$} & $\begin{array}{l}34.70 \pm 5.838 \\
35.76 \pm 6.564\end{array}$ & \multirow[t]{5}{*}{$<0.001$} \\
\hline & Employee & $29.41 \pm 3.264$ & & $32.46 \pm 4.294$ & & $37.51 \pm 4.002$ & \\
\hline & Self-employed & $27.71 \pm 3.402$ & & $31.60 \pm 4.709$ & & $36.36 \pm 5.877$ & \\
\hline & Unemployed & $27.68 \pm 3.123$ & & $31.17 \pm 4.631$ & & $36.41 \pm 5.410$ & \\
\hline & Others & $28.58 \pm 3.454$ & & $32.21 \pm 4.358$ & & $36.84 \pm 5.125$ & \\
\hline Medical staff & $\begin{array}{l}\text { Yes } \\
\text { No }\end{array}$ & $\begin{array}{l}30.15 \pm 3.332 \\
28.18 \pm 3.413\end{array}$ & $<0.001$ & $\begin{array}{l}32.84 \pm 4.307 \\
31.81 \pm 4.475\end{array}$ & $<0.001$ & $\begin{array}{l}38.03 \pm 3.587 \\
36.55 \pm 5.261\end{array}$ & $<0.001$ \\
\hline chronic diseases & $\begin{array}{l}\text { Yes } \\
\text { No }\end{array}$ & $\begin{array}{l}28.55 \pm 3.455 \\
28.58 \pm 3.493\end{array}$ & 0.894 & $\begin{array}{l}31.75 \pm 4.638 \\
32.07 \pm 4.423\end{array}$ & 0.230 & $\begin{array}{l}36.56 \pm 5.374 \\
36.90 \pm 4.933\end{array}$ & 0.258 \\
\hline Place of residence & $\begin{array}{l}\text { City } \\
\text { Rural }\end{array}$ & $\begin{array}{l}28.70 \pm 3.452 \\
27.86 \pm 3.604\end{array}$ & $<0.001$ & $\begin{array}{l}32.14 \pm 4.416 \\
31.31 \pm 4.654\end{array}$ & 0.003 & $\begin{array}{l}37.01 \pm 4.750 \\
35.82 \pm 6.232\end{array}$ & $<0.001$ \\
\hline \multirow[t]{2}{*}{ The key source of knowledge } & $\begin{array}{l}\text { Radio/TV } \\
\text { Ministry of Health }\end{array}$ & $\begin{array}{l}28.13 \pm 3.613 \\
29.87 \pm 3.207\end{array}$ & \multirow[t]{2}{*}{$<0.001$} & $\begin{array}{l}31.83 \pm 4.396 \\
32.22 \pm 4.709\end{array}$ & \multirow[t]{2}{*}{0.300} & $\begin{array}{l}36.92 \pm 4.832 \\
38.18 \pm 3.879\end{array}$ & \multirow[t]{2}{*}{$<0.001$} \\
\hline & Social media & $28.66 \pm 3.363$ & & $32.13 \pm 4.455$ & & $36.49 \pm 5.308$ & \\
\hline
\end{tabular}

Approximately $85.6 \%$ of the participants always and $10.3 \%$ often covered their mouth and nose with a tissue while coughing and sneezing. Furthermore, $96.5 \%$ of the participants always and often washed hands regularly with soap and water for at least $20 \mathrm{~s}$ and $93 \%$ always and often avoided unnecessary travel. Of participants, $81.1 \%$ always and $12.5 \%$ often did not going to crowded places.

Moreover, $71.6 \%$ of the participants stated that they could always reduce stress and from the remaining $28.4 \%, 18$ participants $(0.9 \%)$ were never capable of controlling stress. The majority of the respondents $(86.6 \%)$ always used masks when facing a suspected patient.

Pearson's correlation coefficient showed that knowledge and its sub-categories were positively correlated $(p<0.01)$. The strength of the correlation between knowledge and using masks $(p<0.001, \mathrm{r}=0.48)$ and transmission routes $(p<0.001, \mathrm{r}=0.48)$ showed to be average and that of total knowledge, symptoms of the disease $(p<0.001, \mathrm{r}=0.630)$, at-risk groups $(p<0.001, \mathrm{r}=0.73)$, and preventive measures $(p<0.001, \mathrm{r}=0.73)$ was high. A positive correlation was found between knowledge, attitude, and practice. However, this correlation was low between knowledge and attitude $(p<0.001, \mathrm{r}=0.21)$ and preventive behaviors $(p<0.001, \mathrm{r}=$ $0.23)$. The correlation between attitude and practice $(p<0.001, r=0.17)$ were shown to be slight and negligible.

\section{Discussion}

The present research is the first study exploring Hormozgan residents' knowledge, attitudes, and practices concerning COVID-19. The participants were primarily women (64.4\%) and more than $50 \%$ had a university degree. 

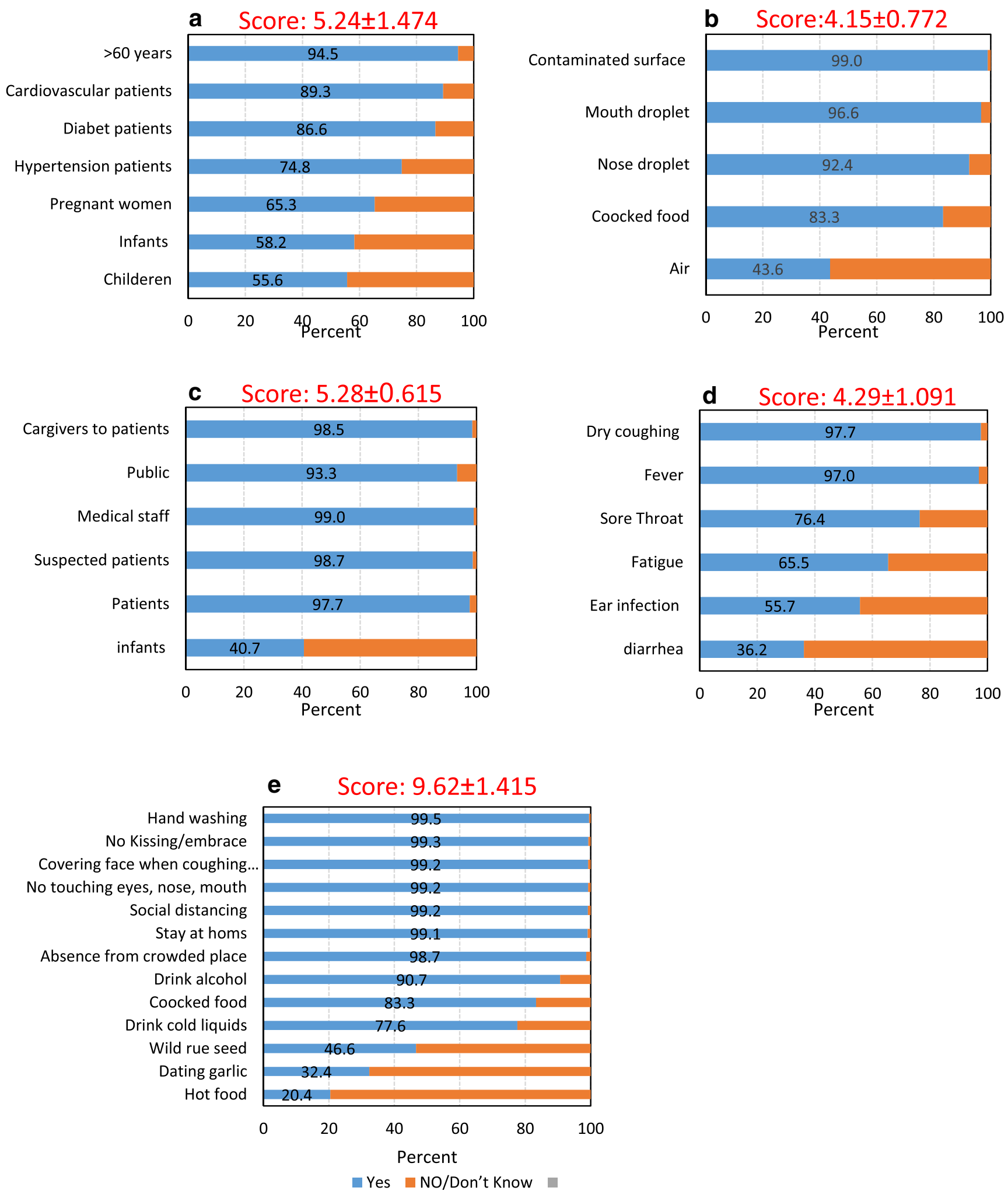

Fig. 1 Participants' knowledge of (a) at risk groups, (b) transmission routes, (c) the need to use a mask, (d) symptoms of the disease, and (e) preventive measures of COVID-19

The key information source of the present participants was found to be the internet as reported in previous studies (Abdelhafiz et al. 2020; Kakemam et al. 2020; Karasneh et al.
2020). This was due to the wide prevalence and active use of social networks. Though improved internet communications can to a great extent increase access to information, it is also 

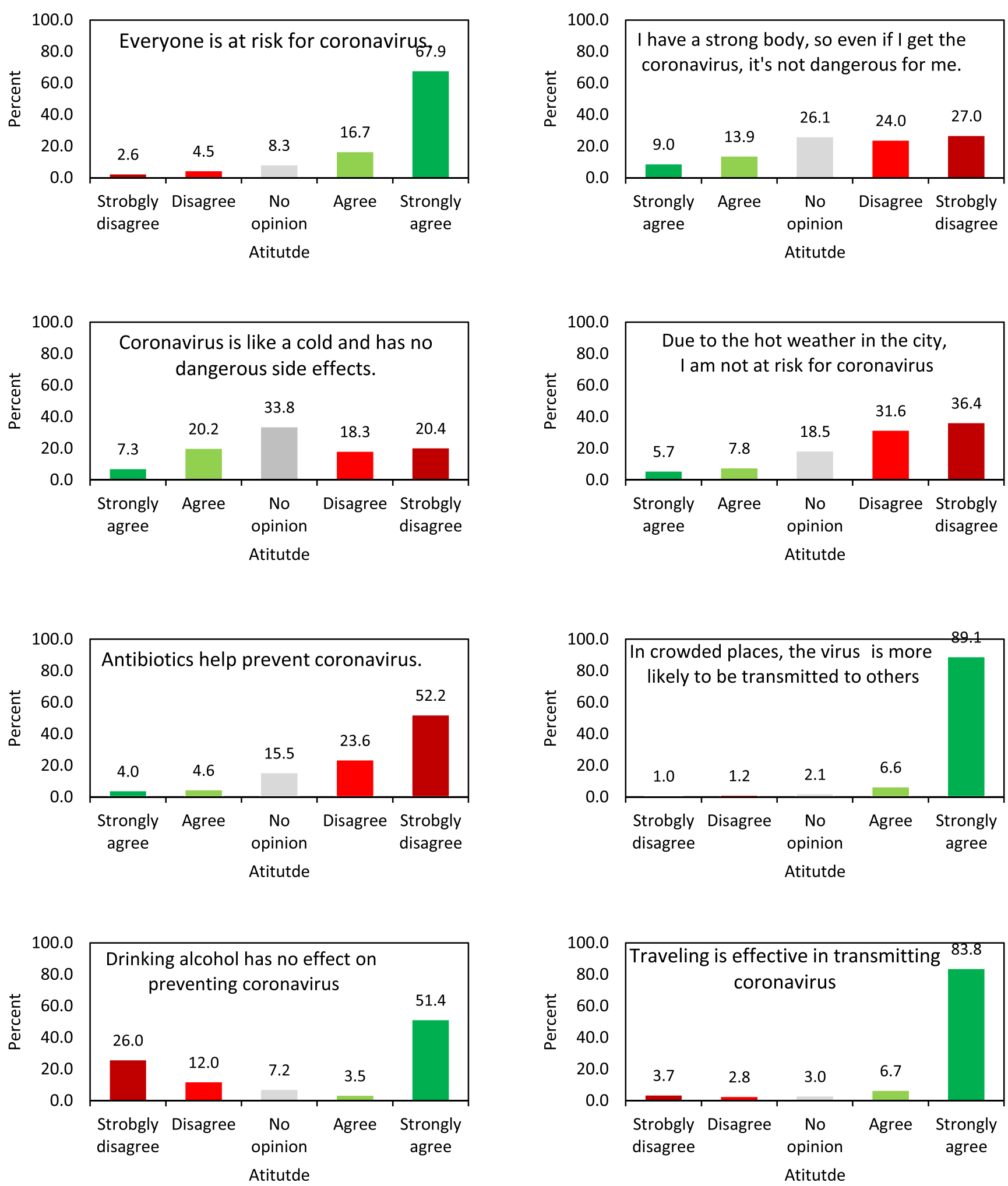

Fig. 2 Participants' attitude toward COVID-19

capable of communicating misleading and erroneous information and even spreading rumors. This can confuse people and lead to public distrust (Abdelhafiz et al. 2020; Karasneh et al. 2020; Lai et al. 2020a; Lai et al. 2020b; Yang et al. 2020).



Of the participants, $65.8 \%$ received a good score of knowledge, which shows that the majority of participants had a good knowledge of COVID-19. The highest mean scores respectively belonged to "What are the transmission routes of 

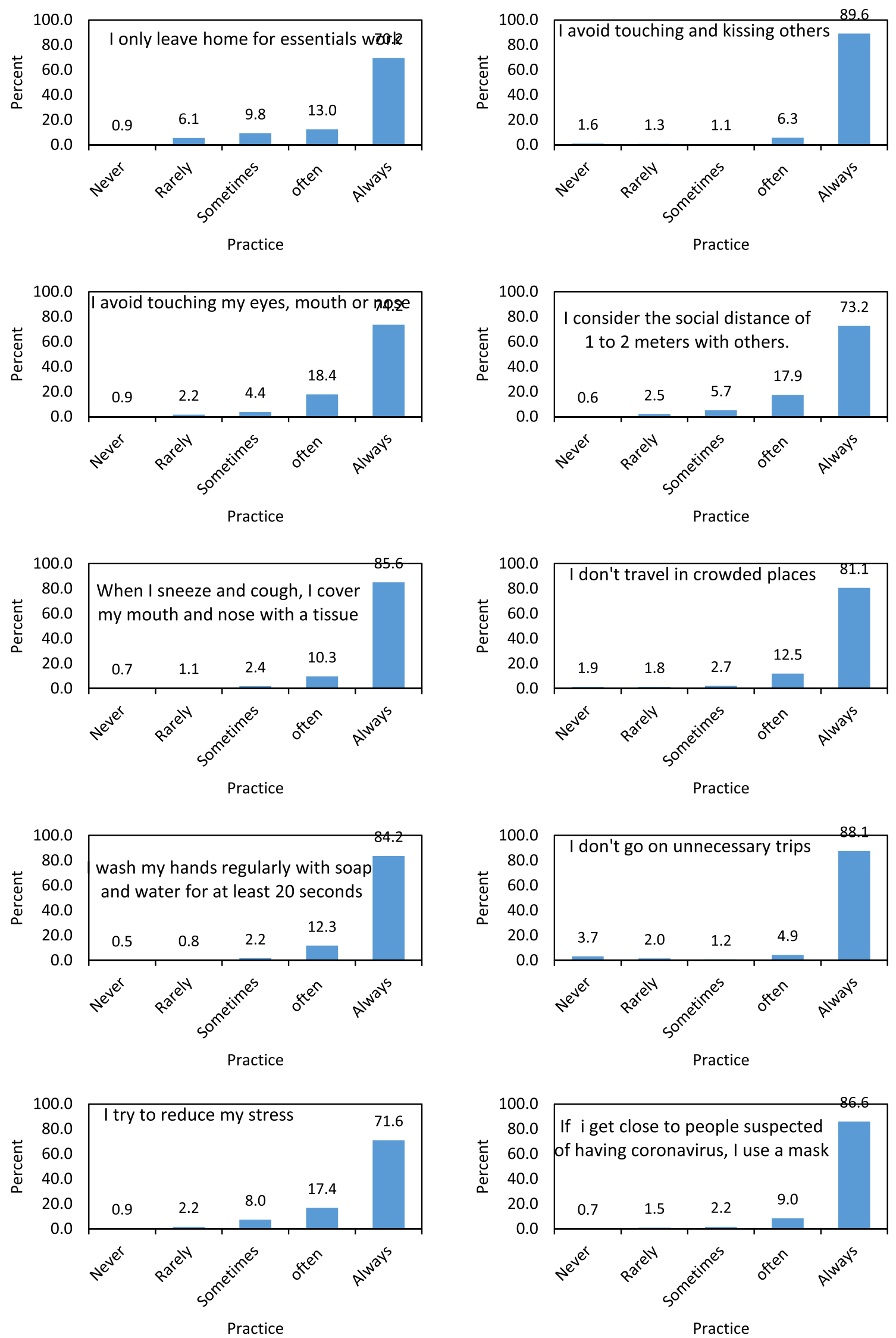

Fig. 3 Participants' practice concerning different aspects of COVID-19 
COVID-19?" (83\%), "How can COVID-19 be prevented?" $(80.17 \%)$, and "Who need to wear masks to prevent COVID-19?" (88\%). Concerning the transmission and prevention routes of the disease, Chen $\&$ Roy also reported the highest percentage of knowledge, which corresponds to the present research (Chen et al. 2020; Roy et al. 2020). In their study of health staff in China, Zhou found $89 \%$ of the participants received a good score of knowledge (Zhou et al. 2020). In a study on Iranian medical students, Taghrir reported a high level of knowledge (86.96\%) (Taghrir et al. 2020). Our finding was in agreement with another study conducted in Iran by Kakemam et al. They reported that awareness and preventive behaviors related to COVID-19 were promoted well in Iran during its outbreak (Kakemam et al. 2020).

There is a wide range of occupations within society. Thus, depending on the nature of jobs, people are differently at risk of transmittable and respiratory diseases (Jiang et al. 2018). The present findings showed different levels of knowledge depending on different jobs and the best knowledge was shown to belong to employees at governmental jobs. This can be due to the most common notifications at work by colleagues and officials.

As the present findings showed, no statistically significant difference was found between attitude and knowledge of males and females. This is incompatible with the studies in China by Zhong, and Hua Gu, yet consistent with the study by Abdelhafiz in Egypt (Abdelhafiz et al. 2020; Gu et al. 2015; Zhong et al. 2020). Despite the fact that the present research had a large sample, the data collection was internet-based and thus urban educated women had better access to the internet, which can be lacking for their rural, uneducated counterparts. This can have affected the results.

The results showed that the largest number of participants were in the age groups 30-40 and 20-30 years old, and the number of old participants was low, which could be due to lack of literacy, lack of mobile and internet facilities, and unwillingness to complete the questionnaire electronically. Studies have shown that the majority of internet users in Iran and worldwide comprise younger age groups (Keykhaie et al. 2014; Langarizadeh et al. 2018; Salehi et al. 2014). This was in line with similar studies (Abdelhafiz et al. 2020; Gu et al. 2015; Zhong et al. 2020).

As the results revealed, more than $97 \%$ of the participants agreed with the essentiality of using masks by patients, suspected patients, medical staff, patients' caregivers, and the public while attending crowded places. In a study in Egypt, approximately $75 \%$ of the participants believed that wearing masks could prevent COVID-19. Only about $35 \%$ were willing to do so. However, in another study in China, upon leaving home, $98 \%$ of the participants wore masks (Abdelhafiz et al. 2020; Zhong et al. 2020). However, WHO recommended wearing masks if respiratory symptoms emerged or when taking care of someone with the symptoms of the disease (Bradley 2006). Despite agreement on recommending symptomatic patients or those in healthcare centers to wear masks, disagreements remain regarding public places and society (Feng et al. 2020). A key reason for discouraging the public to use masks in society is the protection of limited sources for professional use in healthcare places.

The high level of knowledge, despite the fact that this research was done in the early stages of the disease, can be due to the participants' high education level and extensive education provided by the Ministry of Health via TV, the internet, and posters. Unfortunately, due to the impossibility of face-toface data collection and the mere collection of the required data via the internet, the number of rural participants was limited.

In the present study, $63.2 \%$ of the participants demonstrated a positive attitude toward the COVID-19 epidemic. The highest mean scores of attitude were $96.25 \%, 92.84 \%$, and $88.58 \%$, respectively, belonging to the following statements: "The possibility of transmitting coronavirus is higher in crowded places," "Travelling is effective in transmitting coronavirus," and "Everyone is at risk of coronavirus." These findings were similar to related literature, particularly in terms of avoiding contact with others in crowded places (Abdelhafiz et al. 2020; Roy et al. 2020; Zhou et al. 2020). This shows that knowledge directly affects the attitude. The higher the knowledge, the better the attitude toward the disease.

In the present research, women, those with a university degree, healthcare or medical staff, and urban residents demonstrated a better attitude. In another similar study, a high attitude score was associated with preventive actions concerning COVID-19. The majority of participants who enjoyed a relatively high economic status, especially women, had a good knowledge and positive attitude toward COVID19 and showed appropriate practices accordingly (Zhong et al. 2020).

Approximately $75 \%$ of the participants believed that antibiotics were not to be used to prevent the disease. This finding is consistent with an Egyptian study in which $68 \%$ disagreed with the use of antibiotics to prevent the disease. (Abdelhafiz et al. 2020).

Attitude is a predictor of behavioral intention, while intention is considered as a predictor of behavior (McEachan et al. 2016). In addition to the level of knowledge, certain factors including work experience and type of job affect people's attitude and practice concerning COVID-19 (Zhou et al. 2020). In the present research, among the existing different job categories, university students and office workers demonstrated the highest level of attitude toward COVID-19.

Negative attitude toward COVID-19 can produce a feeling of shame and can consequently lead to not reporting suspected cases. This can, in turn, further accelerate the epidemic. The shame associated with COVID-19 is exacerbated by a fear of death. This negative attitude can be removed by correct 
education and clearly elaborated policy-making in healthcare domain (Abdelhafiz et al. 2020).

As $90 \%$ of the participants received a good score for practice in the questionnaire, the majority of participants began correct preventive practice concerning COVID-19.

In contrary to our results, a low level of practices was reported in a systematic review study. This difference may be due to the good performance of the officials in Hormozgan province in controlling, preventing, providing appropriate supplies (such as masks and disinfectants), and training programs (Saadatjoo et al. 2020).

Here, besides stress management which comprised, on average, $89 \%$ of the scores, the remaining cases reported were all above $90 \%$. In a similar research in Saudi Arabia, the mean practice score obtained was $95 \%$ and represented an appropriate level of practice (Baseer et al. 2016). Another study in Saudi Arabia addressed MERS respiratory disease and similar to the present research found that hand washing was the most common protective action followed by using masks while coughing or sneezing (Al-Hazmi et al. 2018). In a study conducted in China, Chen found that the residents of Anhui province did different actions to prevent and control the COVID19 epidemic. The highest percentages belonged, respectively, to "avoiding crowds and going out" (97.4\%), "wearing mask while out" (93.6\%), and "avoiding crowded and enclosed places" (91.5\%) (Chen et al. 2020). In a similar study in the US, daily behaviors were shown to have changed after the COVID-19 epidemic began. This change of behavior differed in different groups influenced by different demographic characteristics. Black participants living below the poverty line had a lower level of health literacy. They were less concerned about the risk of COVID-19 and were less prepared to defeat the disease (Wolf et al. 2020). Another study with similar results was conducted by Taghrir on Iranian medical university students. The mean score of preventive behaviors was 94.47\% (Taghrir et al. 2020).

Regarding the correlation between demographic characteristics and practice, education level was shown to be a key factor. According to the relevant findings, among different education levels, $94.2 \%$ of participants with a university degree demonstrated the highest rate of preventive behavior. This is in line with some other related studies (Roy et al. 2020). In another study in Jordan, the results were inconsistent with the present research, as the dentist participants, despite a high academic degree and good knowledge of COVID-19, in practice did not take preventive measures to protect dental personnel and other patients (Khader et al. 2020). In another study conducted internationally on dentists with different degrees, high scores of knowledge and practice showed a statistically significant correlation with academic degrees and confirmed the present findings (Kamate et al. 2020).

According to the results, the correlation between gender and practice was not statistically significant. This finding was inconsistent with other similar studies that showed women had more preventive behaviors than men (Baseer et al. 2016; Zhong et al. 2020). Concerning MERS, a study showed that men perceived the risk of MERS higher than women, although there was no statistically significant difference between men and women in terms of the risk of disease. These results are similar to that of the present research (Al-Hazmi et al. 2018).

Due to the correlation between knowledge, attitude, and practice, the results evidently pointed to the significance of knowledge promotion. This can improve attitudes as well as preventive practices. The present results draw attention to the essentiality of improving knowledge, attitudes, and practices of people and health/medical staff concerning epidemic diseases. Different groups require different plans and implementations corresponding to their needs. These findings are consistent with the body of related literature on COVID-19 as well as SARS, MERS, and the flu in different countries (Abdelhafiz et al. 2020; Alfahan et al. 2016; Baseer et al. 2016; Bener and Al-Khal 2004; Chan et al. 2015; Chen et al. 2020; Gu et al. 2015; Nour et al. 2015; Shi et al. 2020; Zhong et al. 2020).

One of the limitations of this research is that the questionnaire survey was conducted only via the internet, which was only available to participants who were literate and had access to the internet.

\section{Conclusion}

The present findings show that the residents of Hormozgan Province enjoy a relatively good level of knowledge, positive attitude, and good practice concerning COVID-19. The majority of the participants were educated and had good knowledge of COVID-19. Preventive measures are probably taken more by these people. Thus, they are more concerned about the risk of COVID-19. Due to the existing limitations, there is a need for further research on the knowledge, attitudes, and practices of those with lower educational and socioeconomic levels.

As the present results revealed, participants' knowledge was primarily increased via social networks and the internet system. This knowledge can be both useful and hazardous. It is recommended to manage social networks and disseminate correct information through them.

Acknowledgements The authors would like to thank all the participants in the study.

Authors' contributions All authors contributed equally to this study.

Funding This research was funded by the Deputy of Research and Technology of Hormozgan University of Medical Sciences. 


\section{Compliance with ethical standards}

Ethics approval This study was approved by the ethics committee of Hormozgan University of Medical Sciences (Code: IR.HUMS.REC.1398.477). Before the data collection, the purpose of the study was explained to the participants.

Competing interests The authors declare that they have no competing interests.

\section{References}

Abdelhafiz AS, Mohammed Z, Ibrahim ME, Ziady HH, Alorabi M, Ayyad M, Sultan EA (2020) Knowledge, perceptions, and attitude of Egyptians towards the novel coronavirus disease (COVID-19). J Community Health 45:881-890. https://doi.org/10.1007/s10900020-00827-7

Adab Z, Azizi M, Solhi M, La M, Irandoost F (2016) Dormitory student's Knowlege and Atittiude about influenza a (H1N1) disease. Rahavard Salamat J 2:10-17

Ajilore K, Atakiti I, Onyenankeya K (2017) College students' knowledge, attitudes and adherence to public service announcements on Ebola in Nigeria: suggestions for improving future Ebola prevention education programmes. Health Educ J 76:648-660. https://doi.org/ 10.1177/0017896917710969

Alfahan A, Alhabib S, Abdulmajeed I, Rahman S, Bamuhair S (2016) In the era of corona virus: health care professionals' knowledge, attitudes, and practice of hand hygiene in Saudi primary care centers: a cross-sectional study. J Community Hosp Intern Med Perspect 6(4). https://doi.org/10.3402/jchimp.v6.32151

Al-Hazmi A, Gosadi I, Somily A, Alsubaie S, Bin Saeed A (2018) Knowledge, attitude and practice of secondary schools and university students toward Middle East respiratory syndrome epidemic in Saudi Arabia: a cross-sectional study. Saudi J Biol Sci 25:572-577. https://doi.org/10.1016/j.sjbs.2016.01.032

Alsahafi AJ, Cheng AC (2016) Knowledge, attitudes and Behaviours of healthcare Workers in the Kingdom of Saudi Arabia to MERS coronavirus and other emerging infectious diseases. Int J Environ Res Public Health 13:1214. https://doi.org/10.3390/ijerph13121214

Backer JA, Klinkenberg D, Wallinga J (2020) Incubation period of 2019 novel coronavirus (2019-nCoV) infections among travellers from Wuhan, China, 20-28 January 2020. Euro Surveill 25:2000062. https://doi.org/10.2807/1560-7917.ES.2020.25.5.2000062

Baseer MA, Ansari SH, AlShamrani SS, Alakras AR, Mahrous R, Alenazi AM (2016) Awareness of droplet and airborne isolation precautions among dental health professionals during the outbreak of corona virus infection in Riyadh city, Saudi Arabia. J Clin Exp Dent 8:e379-e387. https://doi.org/10.4317/jced.52811

Bener A, Al-Khal A (2004) Knowledge, attitude and practice towards SARS. J R Soc Promot Health 124:167-170. https://doi.org/10. $1177 / 146642400412400408$

Bradley C (2006) The quality solution: the Stakeholder's guide to improving health care. Ann Intern Med 144:784. https://doi.org/10. 7326/0003-4819-144-10-200605160-00022

Chan EYY, Cheng CKY, Tam G, Huang Z, Lee P (2015) Knowledge, attitudes, and practices of Hong Kong population towards human a/ H7N9 influenza pandemic preparedness, China, 2014. BMC Public Health 15:943-943. https://doi.org/10.1186/s12889-015-2245-9

Chen Y, Jin YL, Zhu LJ et al (2020) The network investigation on knowledge, attitude and practice about Novel coronavirus pneumonia of the residents in Anhui Province. Zhonghua yu fang yi xue za zhi [Chin J Prev Med] 54:E004. https://doi.org/10.3760/cma.j.issn. 0253-9624.2020.0004
Chinazzi M, Davis JT, Ajelli M et al (2020) The effect of travel restrictions on the spread of the 2019 novel coronavirus (COVID-19) outbreak. Science 368:395-400. https://doi.org/10.1126/science. aba9757

Choi J-S, Kim J-S (2016) Factors influencing preventive behavior against Middle East respiratory syndrome-coronavirus among nursing students in South Korea. Nurse Educ Today 40:168-172. https://doi. org/10.1016/j.nedt.2016.03.006

Feng S, Shen C, Xia N, Song W, Fan M, Cowling BJ (2020) Rational use of face masks in the COVID-19 pandemic. Lancet Respir Med 8: 434-436. https://doi.org/10.1016/S2213-2600(20)30134-X

Gorbalenya AE, Baker SC, Baric RS et al (2020) Severe acute respiratory syndrome-related coronavirus: The species and its viruses - a statement of the Coronavirus Study Group. bioRxiv. https://oi.org/10. $1101 / 2020.02 .07 .937862$

Gu H, Jiang Z, Chen B et al (2015) Knowledge, attitudes, and practices regarding avian influenza a (H7N9) among Mobile phone users: a survey in Zhejiang Province, China. JMIR Mhealth Uhealth 3:e15e15. https://doi.org/10.2196/mhealth.3394

Jiang L, Ng IHL, Ya H, Li D, Tan LWL, Ho HJA, Chen MIC (2018) Infectious disease transmission: survey of contacts between hospital-based healthcare workers and working adults from the general population. J Hosp Infect 98:404 411. https://doi.org/10.1016/j. jhin.2017.10.020

Kakemam E, Ghoddoosi-Nejad D, Chegini Z et al (2020) Knowledge, attitudes, and practices among the general population during COVID-19 outbreak in Iran: a national cross-sectional survey. medRxiv. https://doi.org/10.1101/2020.06.10.20127258

Kamate SK, Sharma S, Thakar S et al (2020) Assessing knowledge, attitudes and practices of dental practitioners regarding the COVID-19 pandemic: a multinational study. Dent Med Prob 57: 11-17. https://doi.org/10.17219/dmp/119743

Karasneh R, Al-Azzam S, Muflih S, Soudah O, Hawamdeh S, Khader Y (2020) Media's effect on shaping knowledge, awareness risk perceptions and communication practices of pandemic COVID-19 among pharmacists. Res Social Adm Pharm. https://doi.org/10. 1016/j.sapharm.2020.04.027

Keykhaie Z, Zareban I, Shahrakipoor M, Hormozi M, Sharifi-Rad J, Masoudi G, Rahimi F (2014) Implementation of internet training on posture reform of computer users in Iran. Acta Inform Med 22: 379-384. https://doi.org/10.5455/aim.2014.22.379-384

Khader Y, Al Nsour M, Al-Batayneh OB et al (2020) Dentists' awareness, perception, and attitude regarding COVID-19 and infection control: cross-sectional study among Jordanian dentists. JMIR Public Health Surveill 6:e18798. https://doi.org/10.2196/18798

Kim M (2017) The convergence study of nursing Students' knowledge, attitudes and preventive behaviors against MERS in South Korea. J Korea Convergence Soc 8:149-157. https://doi.org/10.15207/ JKCS.2017.8.4.149

Lai C-C, Liu YH, Wang C-Y et al (2020a) Asymptomatic carrier state, acute respiratory disease, and pneumonia due to severe acute respiratory syndrome coronavirus 2 (SARS-CoV-2): facts and myths. J Microbiol Immunol Infect. https://doi.org/10.1016/j.jmii.2020.02. 012

Lai C-C, Shih T-P, Ko W-C, Tang H-J, Hsueh P-R (2020b) Severe acute respiratory syndrome coronavirus 2 (SARS-CoV-2) and coronavirus disease-2019 (COVID-19): the epidemic and the challenges. Int J Antimicrob Agents 55:105924-105924. https://doi.org/10.1016/j. ijantimicag.2020.105924

Lake M (2020) What we know so far: COVID-19 current clinical knowledge and research. Clin Med 20:124-127. https://doi.org/10.7861/ clinmed.2019-coron

Langarizadeh M, Naghipour M, Tabatabaei SM, Mirzaei A, Vaghar ME (2018) Prediction of internet addiction based on information literacy among students of Iran University of Medical Sciences. Electron Physician 10:6333-6340. https://doi.org/10.19082/6333 
Lauer SA, Grantz KH, Bi Q et al (2020) The incubation period of coronavirus disease 2019 (COVID-19) from publicly reported confirmed cases: estimation and application. Ann Intern Med 172:577-582. https://doi.org/10.7326/m20-0504

McEachan R, Taylor N, Harrison R, Lawton R, Gardner P, Conner M (2016) Meta-analysis of the reasoned action approach (RAA) to understanding health behaviors. Ann Behav Med 50:592-612. https://doi.org/10.1007/s12160-016-9798-4

Nour M, Babilghith A, Natto H, Elamin F, Alawneh S (2015) Knowledge, attitude and practices of healthcare providers towards MERS-CoV infection at Makkah hospitals, KSA. Int Res J Med Med Sci 3:103-112

Person B, Sy F, Holton K, Govert B, Liang A (2004) Fear and stigma: the epidemic within the SARS outbreak. Emerg Infect Dis 10:358-363. https://doi.org/10.3201/eid1002.030750

Roy D, Tripathy S, Kar SK, Sharma N, Verma SK, Kaushal V (2020) Study of knowledge, attitude, anxiety \& perceived mental healthcare need in Indian population during COVID-19 pandemic. Asian J Psychiatr 51:102083. https://doi.org/10.1016/j.ajp.2020.102083

Saadatjoo S, Miri M, Hassanipour S, Ameri H, Arab-Zozani M (2020) A systematic review of the knowledge, attitudes, and practices of physicians, health workers, and the general population about coronavirus disease 2019 (COVID-19). medRxiv. https://doi.org/10.1101/ 2020.10.04.20206094

Salehi M, Norozi Khalili M, Hojjat SK, Salehi M, Danesh A (2014) Prevalence of internet addiction and associated factors among medical students from Mashhad, Iran in 2013. Iran Red Crescent Med J 16:e17256. https://doi.org/10.5812/ircmj.17256

Shahzad F, Shahzad U, Fareed Z, Iqbal N, Hashmi SH, Ahmad F (2020) Asymmetric nexus between temperature and COVID-19 in the top ten affected provinces of China: a current application of quantile-onquantile approach. Sci Total Environ 736:139115. https://doi.org/ 10.1016/j.scitotenv.2020.139115

Shi Y, Wang J, Yang Y et al (2020) Knowledge and attitudes of medical staff in Chinese psychiatric hospitals regarding COVID-19. Brain Behav Immun Health 4:100064. https://doi.org/10.1016/j.bbih. 2020.100064

Taghrir MH, Borazjani R, Shiraly R (2020) COVID-19 and Iranian medical students; a survey on their related-knowledge, preventive behaviors and risk perception. Arch Iran Med 23:249-254. https://doi. org/10.34172/aim.2020.06

Tao J, Song Z, Yang L, Huang C, Feng A, Man X (2020) Emergency management for preventing and controlling nosocomial infection of 2019 novel coronavirus: implications for the dermatology department. Br J Dermatol. https://doi.org/10.1111/bjd.19011
Tosepu R, Gunawan J, Effendy DS, Ahmad LOAI, Lestari H, Bahar H, Asfian P (2020) Correlation between weather and Covid-19 pandemic in Jakarta, Indonesia. Sci Total Environ 725:138436. https://doi.org/10.1016/j.scitotenv.2020.138436

WHO (2020a) WHO Coronavirus Disease (COVID-19), 16 November 2020, Dashboard. https://covid19.who.int/

WHO (2020b) WHO Director-General's remarks at the media briefing on 2019-nCoV on 11 February 2020. https://www.who.int/dg/ speeches/detail/who-director-general-s-remarks-at-the-mediabriefing-on-2019-ncov-on-11-February-2020

Wolf MS, Serper M, Opsasnick L et al (2020) Awareness, attitudes, and actions related to COVID-19 among adults with chronic conditions at the onset of the U.S. outbreak: a cross-sectional survey. Ann Intern Med:M20-1239. https://doi.org/10.7326/M20-1239

Wu F, Zhao S, Yu B et al (2020) Complete genome characterisation of a novel coronavirus associated with severe human respiratory disease in Wuhan, China. bioRxiv. https://doi.org/10.1101/2020.01.24. 919183

Xiao Z, Xie X, Guo W et al (2020) Examining the incubation period distributions of COVID-19 on Chinese patients with different travel histories. J Infect Dev Countries 14:323-327. https://doi.org/10. 3855/jidc. 12718

Yaghubi M, Sharifi S, Abbaspour H (2014) Knowledge, attitude, and practice of intensive care units nurses about nosocomial infections control in hospitals of Bojnurd in 2012. J North Khorasan Univ Med Sci 5:943-950. https://doi.org/10.29252/jnkums.5.5.S5.943

Yang Y, Peng F, Wang R et al (2020) The deadly coronaviruses: the 2003 SARS pandemic and the 2020 novel coronavirus epidemic in China. J Autoimmun 109:102434-102434. https://doi.org/10.1016/j.jaut. 2020.102434

Zhong B-L, Luo W, Li H-M, Zhang Q-Q, Liu X-G, Li W-T, Li Y (2020) Knowledge, attitudes, and practices towards COVID-19 among Chinese residents during the rapid rise period of the COVID-19 outbreak: a quick online cross-sectional survey. Int J Biol Sci 16: 1745-1752. https://doi.org/10.7150/ijbs.45221

Zhou M, Tang F, Wang Y, Nie H, Zhang L, You G, Zhang M (2020) Knowledge, attitude and practice regarding COVID-19 among health care workers in Henan, China. J Hosp Infect. https://doi.org/ 10.1016/j.jhin.2020.04.012

Publisher's note Springer Nature remains neutral with regard to jurisdictional claims in published maps and institutional affiliations. 